\title{
Nucleation of atmospheric particles
}

\author{
J. Curtius
}

Institute for Atmospheric and Environmental Sciences, Goethe-University of Frankfurt, Frankfurt am Main, Germany

\begin{abstract}
Two types of particles exist in the atmosphere, primary and secondary particles. While primary particles such as soot, mineral dust, sea salt particles or pollen are introduced directly as particles into the atmosphere, secondary particles are formed in the atmosphere by condensation of gases. The formation of such new aerosol particles takes place frequently and at a broad variety of atmospheric conditions and geographic locations. A considerable fraction of the atmospheric particles is formed by such nucleation processes. The newly formed particles may grow by condensation to sizes where they are large enough to act as cloud condensation nuclei and therefore may affect cloud properties. The fundamental processes of aerosol nucleation are described and typical atmospheric observations are discussed. Two recent studies are introduced that potentially change our current understanding of atmospheric nucleation substantially.
\end{abstract}

\section{Introduction}

When a cloud forms in the atmosphere, water molecules condense. In cloud formation processes, typically an air parcel is ascending and therefore temperature drops and relative humidity rises due to the expansion of the air parcel. As soon as a relative humidity of $100 \%$ is reached, tiny cloud droplets start to form. The condensing water molecules do not form new droplets but the water always condenses on already existing particles. This is, because it is energetically more favourable for the water molecules to condense on pre-existing particle surfaces, rather than forming new particles on their own due to the involved surface energy. These particles on which the water condenses are called the cloud condensation nuclei (CCN). A large fraction of all the particles that float in the atmosphere can act as cloud condensation nuclei already at very small supersaturations of around $100.05 \%$ to $100.5 \%$ relative humidity. Whether a particle can act as a cloud condensation nuclei is determined mostly by its size (the larger, the easier the activation at very small supersaturations) and to some extent by its chemistry and morphology [1]. However, in the troposphere there are always enough particles around that can act as cloud condensation nuclei so that clouds never form in the atmosphere via the formation of new, pure water droplets. A supersaturation corresponding to several hundred percent of relative humidity would be required for new water droplets to form in the atmosphere [2].

Nevertheless, there are some - few - substances in the atmosphere that are able to form new particles. By now it is well known that new particle formation occurs frequently in the atmosphere and a good fraction of all the particles present have formed by nucleation. New particle formation has been observed at numerous places with very different climatologic conditions, such as boreal forests [3], coastal areas [4,5], urban areas [6], or the free troposphere [7-10]. At some of these places distinct particle nucleation events can be observed almost every day $[4,11,12]$.

Numerous investigations have been conducted to study these particle formation events [13]. Significant progress has been achieved in understanding the physical processes taking place

Article published by EDP Sciences and available at http://www.epj-conferences.org

or http://dx.doi.org/10.1140/epjconf/e2009-00921-0 


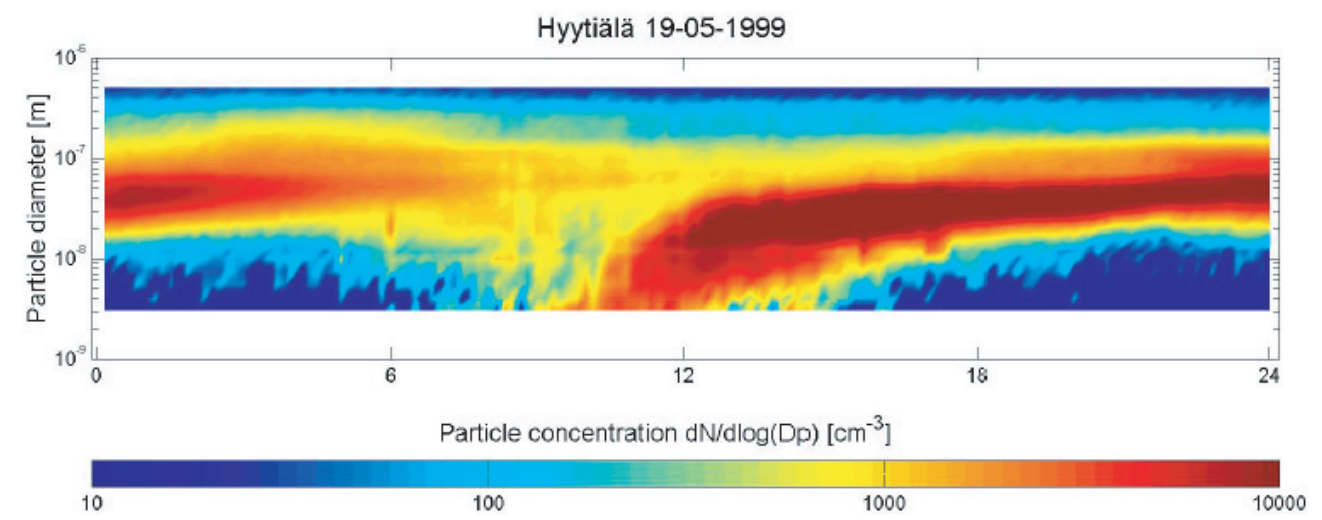

Fig. 1. A typical particle nucleation event is detected when plotting the particle concentration as a function of time and particle size for measurement observed in a boreal forest at Hyytiälä, Finland, for 19 May 1999. Between 9:00 and 12:30 numerous freshly nucleated particles appear at the smallest measurable sizes $(>3 \mathrm{~nm})$ and grow within hours to sizes of around $50 \mathrm{~nm}$. From [16].

during atmospheric particle nucleation as well as concerning the chemical substances involved in the nucleation and the subsequent growth of the particles. Different theoretical approaches have been developed to describe the nucleation process and a variety of modelling efforts have been undertaken to simulate nucleation, ranging from the microphysical level up to inclusion of nucleation in global chemistry and climate models. Nevertheless, the particle nucleation process itself, the clustering of molecules in the atmosphere remains to be difficult to study experimentally, as there is hardly any instrumentation available to measure and characterize these molecular clusters at atmospheric conditions, and many open questions remain on the nucleation mechanism and the involved chemical substances, as we will see in the following sections. For a more detailed introduction to the subject of atmospheric aerosol nucleation, the reader is referred to more comprehensive introductions and reviews $[2,14,15]$.

A precondition for nucleation to take place is that the substances that nucleate have to be supersaturated in the gas phase. But supersaturation alone is not enough, it must be highly supersaturated such that on the one hand the nucleation barrier (see below) can be overcome and on the other hand the nucleating molecules have to cluster faster than being lost to the pre-existing aerosol particles that are always abundant in the atmosphere. Apparently, this condition is only reached occasionally and only for a few substances.

The most important processes that can cause supersaturation of substances in the atmosphere are photochemical processes. In this case a highly volatile substance is converted in the gas phase into a less volatile, typically more oxidized substance. For example, sulphur dioxide $\left(\mathrm{SO}_{2}\right)$ is oxidized by reaction with the hydroxyl radical $(\mathrm{OH})$ forming gaseous sulphuric acid $\left(\mathrm{H}_{2} \mathrm{SO}_{4}\right)$. The sulphuric acid has a low vapour pressure and therefore it is easily supersaturated in the gas phase and a rapid transfer into the condensed phase takes place. If there are not enough preexisting aerosol particles around on which the sulphuric acid can condense, then new particles are formed. In fact, in the atmosphere there is always water vapour abundant and due to the large enthalpy of mixing for the sulphuric acid/water system, the actual nucleation process will always involve the co-condensation of sulphuric acid and water. Therefore, such a nucleation process is called binary homogeneous nucleation. "Binary" because two substances, sulphuric acid and water, are involved, "homogeneous" because new particles are formed without the involvement of any pre-existing surface. A third substance, such as ammonia $[17,18]$ or an organic acid [19] can enhance the nucleation of $\mathrm{H}_{2} \mathrm{SO}_{4}$ and $\mathrm{H}_{2} \mathrm{O}$ even further, if present. In this case the nucleation mechanism would be called ternary homogeneous nucleation.

Because the aerosol influences climate directly [20] and indirectly via the cloud formation processes [21], as well as because of adverse health effects of ultrafine particles [22,23], it is very important to gain a deeper understanding of nucleation processes and to include these processes in global climate and chemistry models. 


\section{Atmospheric observations}

The occurrence of new particles is usually detected as a so-called nucleation event. Figure 1 shows such a nucleation event as it is frequently observed at a measurement station located in a boreal forest in Hyytiälä, Finland. The figure shows a contour plot of the measured particle size distribution as a function of time. While hardly any particles exist that are smaller than $10 \mathrm{~nm}$ for most of the time, suddenly in the late morning numerous particles of $3-10 \mathrm{~nm}$ size are detected. Over the day, these particles grow by condensation of further condensable gases and coagulation among the particles and the population of the smallest particle sizes is depleted again. After about noon time, no new particles are detected any more at the smallest particle sizes. The particles of $3-10 \mathrm{~nm}$ size must have been produced recently by particle nucleation from the gas phase. These particles are too small to be primary particles and they must have formed recently as such small particles collide within a few hours with larger particles and are therefore lost.

Typical nucleation events produce about 1 particle $\mathrm{cm}^{-3} \mathrm{~s}^{-1}$ and concentrations of a few thousand freshly formed particles per cubic centimetre are usually detected after a nucleation event [13]. The growth rate of the particles after nucleation is on the order of $1 \mathrm{~nm} \mathrm{hr}^{-1}[13]$. In most cases, the nucleation takes place during daytime, preferentially in the late morning because photolytic processes like the formation of $\mathrm{OH}$ are involved in the occurrence of the precursor gases that form the new particles.

The formation of new particles from gaseous sulphuric acid and water is thought to be the most important atmospheric nucleation process. How is the gas phase sulphuric acid produced? The largest fraction of the $\mathrm{SO}_{2}$ in the atmosphere is oxidized to sulphate in the liquid phase by chemical reactions in cloud droplets. However, a fraction is converted into sulphuric acid in the gas phase by reaction with the hydroxyl radical OH $[24,25]$ :

$$
\begin{gathered}
\mathrm{SO}_{2}+\mathrm{OH}+\mathrm{M} \rightarrow \mathrm{HOSO}_{2}+\mathrm{M} \\
\mathrm{HOSO}_{2}+\mathrm{O}_{2} \rightarrow \mathrm{SO}_{3}+\mathrm{HO}_{2} \\
\mathrm{SO}_{3}+2 \mathrm{H}_{2} \mathrm{O} \rightarrow \mathrm{H}_{2} \mathrm{SO}_{4}+\mathrm{H}_{2} \mathrm{O} .
\end{gathered}
$$

This gas phase sulphuric acid is assumed to be the key for many aerosol nucleation events observed in the atmosphere and we will focus our description on this substance. A strong correlation between the gas phase sulphuric acid and nucleation-mode particles in the $3-6 \mathrm{~nm}$ size range is often observed. This suggests that sulphuric acid is taking part in the nucleation of the particles [26,27].

A schematic for the formation of new particles from sulphuric acid and water vapour is shown in Figure 2. For the nucleation events observed in boreal forests it has been found that the sulphuric acid concentration is usually too low (typically $10^{6}-10^{7}$ molecules $^{-3}$ ) to contribute more than a few percent to the observed subsequent particle growth after the initial particle nucleation has occurred (overcoming of the nucleation barrier, see below) [28]. Once formed and thermodynamically stable, other substances such as condensable oxidized organic compounds take part in the growth of the newly formed particles and contribute the largest mass fraction of the particles. Therefore, the formation of atmospheric new particles is often divided into a two-step process: First the nucleation itself where clusters overcome the nucleation barrier, and then the subsequent growth of these clusters. For the nucleation events that occur in boreal forest regions, it has been shown, for example, that terpene oxidation products from substances such as alpha-pinene, beta-pinene or limonene play an important role for the observed growth of particles after nucleation. The terpenes are emitted by the trees in fairly large amounts.

Besides sulphuric acid, also iodine oxides, particularly OIO, can produce aerosol particles in the atmosphere. Iodine compounds are emitted into the atmosphere from macro algae during low tide and massive nucleation bursts occur in some coastal areas such as the west coast of Ireland on an almost daily basis $[4,5,29]$.

Nucleation depends non-linearly on many parameters, such as the concentration of the precursor gases, the temperature and the surface area of the pre-existent aerosol. Therefore a 


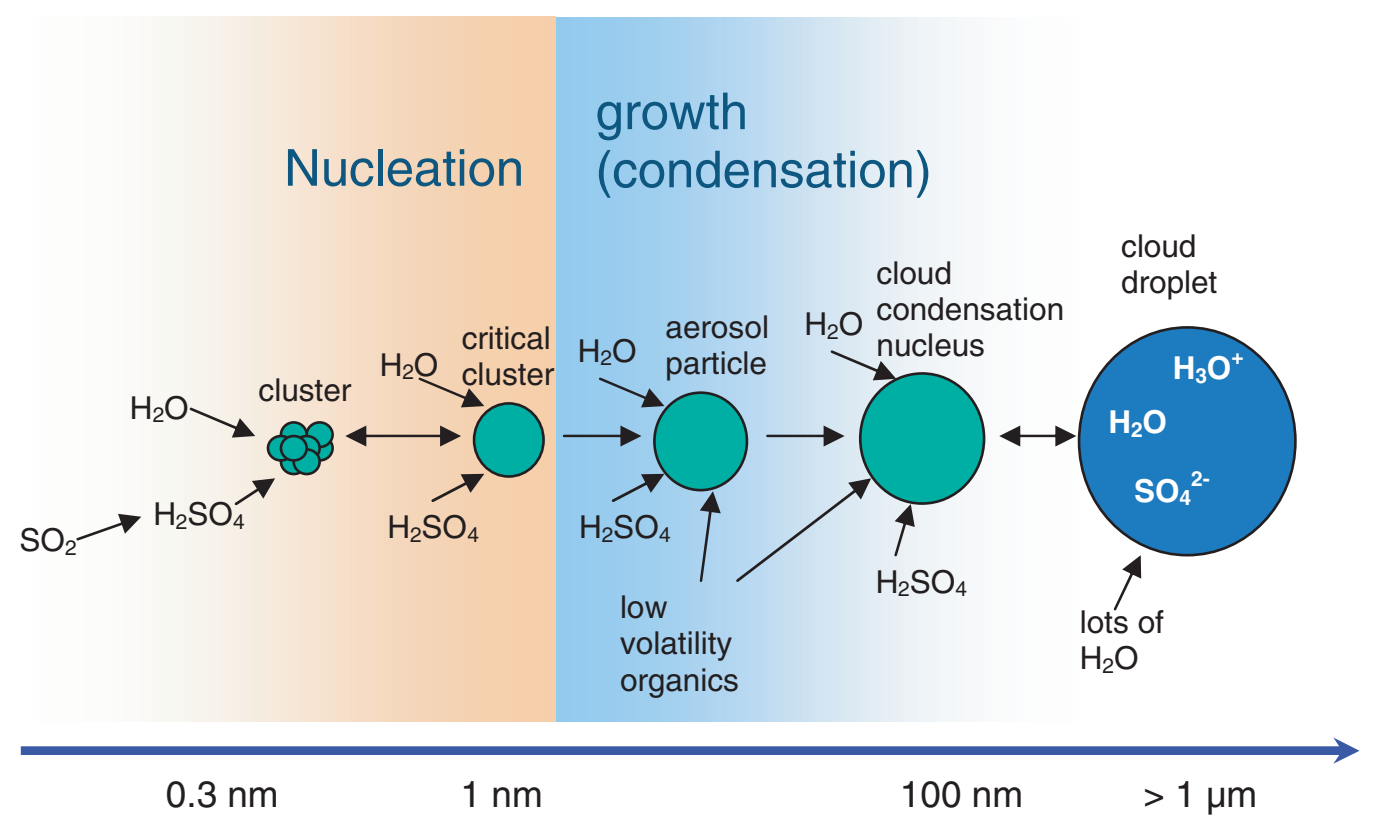

Fig. 2. Schematic representation of the nucleation and subsequent growth process for atmospheric binary homogeneous nucleation of $\mathrm{H}_{2} \mathrm{SO}_{4}$ and $\mathrm{H}_{2} \mathrm{O}$. Once thermodynamically stable clusters larger than the so-called critical cluster have formed, also other substances such as low-volatility organics can take part in the growth process. Particles may grow further to sizes large enough to act as cloud condensation nuclei on which cloud droplets may form eventually. From [14].

comprehensive theoretical description and the treatment of aerosol nucleation in global chemistry models remain very challenging. Reasonable success in including nucleation in a global model has recently been achieved by Spracklen et al. [30,31].

\section{Nucleation theory}

How can the formation of aerosol particles be described thermodynamically? Classical nucleation theory to describe aerosol formation still forms the basis for the thermodynamic interpretation of aerosol nucleation processes. The Gibbs free energy $G$ is studied to characterize the atmospheric nucleation processes as the natural variables pressure and temperature can easily be measured. For a given, fixed pressure and temperature, a closed thermodynamic system will drive towards a state in which $G$ is minimal. Let us start by looking at the nucleation process for a single substance $A$, for example, pure sulphuric acid. This can be extended to - atmospherically more relevant - binary and ternary systems but, for simplicity, let us consider just the single component system. Substance $A$ has a vapour pressure $p_{A}$. Its equilibrium vapour pressure over a flat surface of the bulk liquid $A$ is $p_{A \infty}$. If the substance is supersaturated in the gas phase $\left(p_{A}>p_{A \infty}\right)$ and far away from any other surfaces on which the gas phase molecules could condense on, the system is meta-stable and the vapour molecules would generally prefer to undergo a phase transition to the condensed phase as a lower value of $G$ could be obtained due to the lower chemical potential of the bulk liquid. For a single substance the thermodynamics of the nucleation is then given by [2]:

$$
\Delta G=-\frac{4}{3} \pi R_{p}^{3} \frac{k T}{v_{l}} \ln S+4 \pi R_{p}^{2} \sigma .
$$

This equation gives the change of the free energy $G$ as a function of the nucleating particle's radius $R_{p}$. Here $S$ is the saturation ratio, $S=p_{A} / p_{A \infty}, k$ is the Boltzmann constant, $T$ is the temperature, $v_{l}$ is the volume occupied per molecule, and $\sigma$ is the surface tension of substance A. 


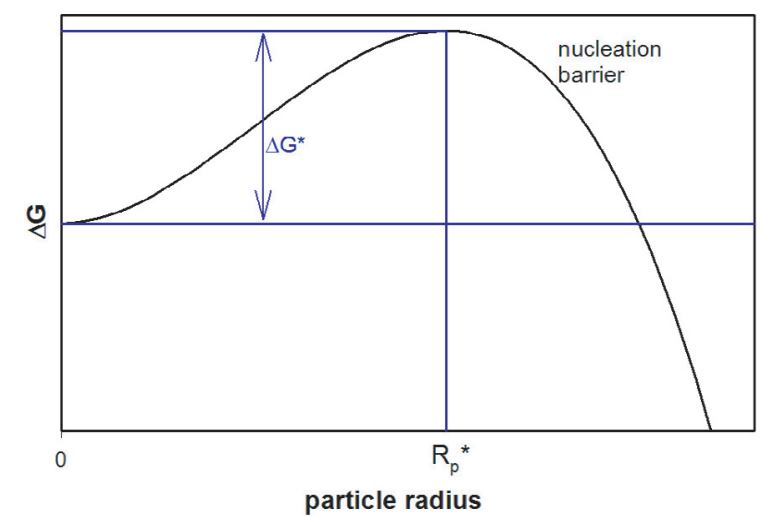

Fig. 3. Thermodynamic representation of aerosol nucleation for a single chemical compound. A nucleation barrier of height $\Delta G^{*}$ exists. The critical cluster size $R_{p}^{*}$ is defined by the maximum of the barrier. From [14].

The equation is illustrated by Figure 3. As long as the system is supersaturated, $S$ is larger than 1 and the first term of the right hand side of the equation is negative. Generally, this is the driving force for the gas phase molecules to condense and thereby increase the particle's radius. Just in the beginning, for small $R_{p}$, the second term plays an important role. As the particle forms, a new surface $\left(\mathrm{A}_{\mathrm{p}}=4 \pi R_{p}^{2}\right)$ has to be build up, costing surface energy. In the beginning this surface energy is bigger than the energy won from changing from gas phase to particle phase and therefore for small $R_{p}$ an effective energy barrier exists (the so-called nucleation barrier) that prevents the gas from nucleation although it is supersaturated in the gas phase with respect to the flat surface equilibrium pressure.

The location of the maximum of the barrier marks the critical radius. Once a cluster has reached the size of the critical cluster, the droplet will persist and most likely grow further by condensation of further gas phase molecules. For small clusters with sizes smaller than the critical size it is energetically more likely to evaporate off a molecule than another molecule condensing on them. In most cases such clusters will fall apart into separate gas molecules again. But there is a statistical chance that now and then a cluster collects so many molecules that it becomes large enough to reach the critical size and overcome the barrier.

From differentiation of equation (1) the height of the nucleation barrier $\Delta G^{*}$ and the position of the critical radius $R_{p}^{*}$ can be determined:

$$
\Delta G^{*}=\frac{4 \pi}{3} \sigma R_{p}^{* 2}=\frac{4 \pi}{3} \sigma\left(\frac{2 \sigma v_{l}}{k T \ln S}\right)^{2}
$$

This equation is known as the Kelvin equation. Just at the critical radius a particle has reached an instable equilibrium and will neither grow nor evaporate. Therefore the Kelvin equation connects also the equilibrium vapour pressure $\mathrm{p}_{\mathrm{A}}^{*}$ of $\mathrm{A}$ over a spherical surface of radius $R_{p}^{*}$ with the equilibrium vapour pressure over a flat surface $\mathrm{p}_{\mathrm{A} \infty}$. Although the classical nucleation theory has been quite successful in describing the nucleation process in general, it has to be noted that large differences exist between atmospheric observations and predictions by classical theory. There are several factors responsible for these discrepancies. On the one hand side, classical theory is limited and the bulk phase parameters like surface tension and density that enter into the classical equations are not suitable to describe the molecular clusters correctly $[32,33]$. By now, some more sophisticated approaches exist, but agreement between atmospheric measurement and theory is usually still not satisfactory. This limited agreement is not only caused by the incomplete theory but also by the fact that the chemical compounds that actually cause the nucleation as well as the concentration, size and composition of the freshly nucleated cluster $<3 \mathrm{~nm}$ can usually not be measured. 


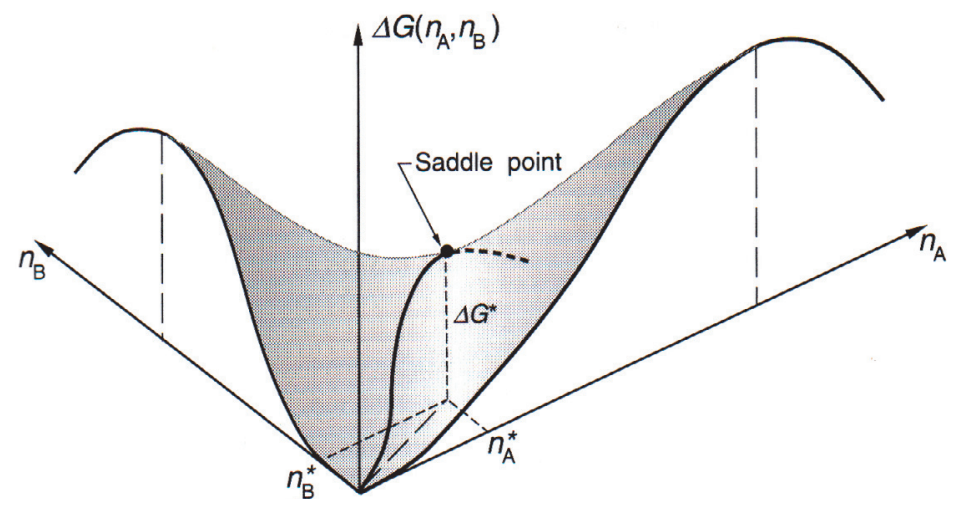

Fig. 4. For the binary homogeneous nucleation of the two compounds A and B with the number of molecules of type $\mathrm{A}$ and $\mathrm{B}$ in the cluster given by $\mathrm{n}_{\mathrm{A}}$ and $\mathrm{n}_{\mathrm{B}}$, the $\Delta \mathrm{G}$ curve shown in Figure 3 expands into a saddle-shaped surface. The position of the nucleation barrier is located at the saddle point. From [2].

The nucleation rate $\mathrm{J}$ is given as the number of clusters that grow beyond the critical size per second. The nucleation rate is connected to the height of the nucleation barrier by:

$$
\mathrm{J}=\mathrm{C} \exp \left(-\frac{\Delta G^{*}}{k T}\right)
$$

Here, $\mathrm{C}$ is a preexponential factor. There is a negative exponential dependence of the nucleation rate on the height of the nucleation barrier. The nucleation barrier determines the nucleation processes. As mentioned in the beginning, pure water vapour will never undergo homogeneous nucleation in the lower atmosphere as the nucleation barrier will always be much too high and no clusters will overcome this barrier at atmospheric supersaturations. Similarly, the condensable oxidation products of the terpenes described in the previous section are considered to not being able to form new particles on their own at their maximum atmospheric concentrations.

The fundamental nucleation theorem connects the number of molecules $\mathrm{n}_{\mathrm{A}}^{*}$ of species $\mathrm{A}$ that form the critical cluster with the slope of the logarithm of the nucleation rate as a function of the logarithm of the saturation $\mathrm{S}$ of the nucleating species [34-36]:

$$
\left[\frac{\partial \ln J}{\partial \ln S_{A}}\right]_{T} \approx n_{A}
$$

This expression can be extended to binary systems [35]. It means, for example, that for binary nucleation of $\mathrm{H}_{2} \mathrm{SO}_{4}$ and $\mathrm{H}_{2} \mathrm{O}$ the number of $\mathrm{H}_{2} \mathrm{SO}_{4}$ molecules in the critical cluster can be derived from measurements of the nucleation rate as a function of the $\mathrm{H}_{2} \mathrm{SO}_{4}$ concentration at fixed temperature and relative humidity $[17,36]$. As an example, Figure 4 shows the measured nucleation rate $J$ as a function of the sulphuric acid concentration and the derived number of molecules of the critical cluster.

The above equations are given for homogeneous systems consisting of one substance only. In the atmosphere often two, three or even more substances are involved in the nucleation process, as the equilibrium vapour pressures of mixed systems are generally lower than for the pure systems. The nucleation of sulphuric acid and water is assumed to be the most important binary system for the atmosphere. The nucleation theory has been expanded to the binary system [37-41]. Here, the $\Delta G$ curve of Figure 3 becomes a saddle-shaped surface, when $\Delta G$ is plotted as a function of the two components and the composition of the critical cluster is defined by the saddle point (see Figure 5). Further components like $\mathrm{NH}_{3}$ can facilitate the nucleation even further, and, in the presence of ammonia, the number of $\mathrm{H}_{2} \mathrm{SO}_{4}$ molecules in the critical cluster is further reduced (Figure 4).

A further nucleation mechanism that is thought to be of importance in the atmosphere is ion-induced nucleation. Here, the cluster forms around an ion. The charge helps to stabilize the cluster as molecules do not evaporate from the cluster as easily as for nucleation without 


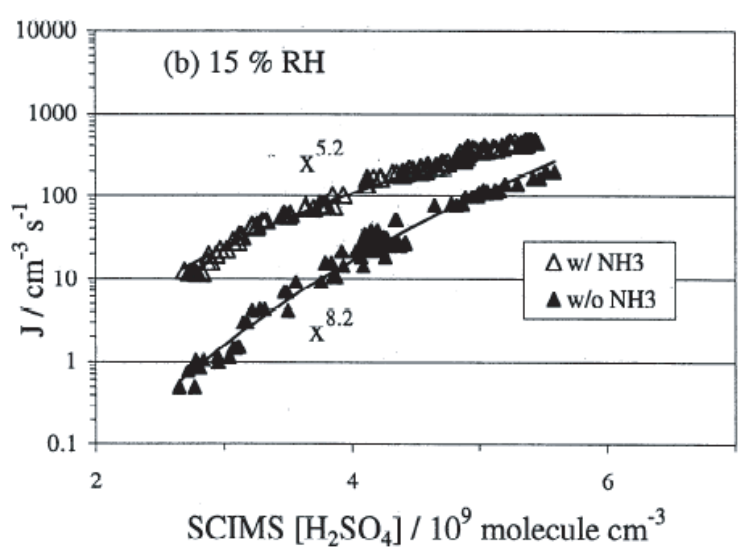

Fig. 5. Laboratory measurement of binary homogeneous nucleation for $\mathrm{H}_{2} \mathrm{SO}_{4}$ and $\mathrm{H}_{2} \mathrm{O}$ (full symbols) and for the ternary system $\mathrm{H}_{2} \mathrm{SO}_{4} / \mathrm{H}_{2} \mathrm{O} / \mathrm{NH}_{3}$ (open symbols). Dependence of the nucleation rate as a function of sulphuric acid concentration. According to the nucleation theorem $\mathrm{J}=$ const $\times\left[\mathrm{H}_{2} \mathrm{SO}_{4}\right]^{\mathrm{n} *}$, the slope gives the number of $\mathrm{H}_{2} \mathrm{SO}_{4}$ molecules in the critical cluster. Here a number of $\mathrm{n}^{*}=8.2 \mathrm{H}_{2} \mathrm{SO}_{4}$ molecules for the binary and $\mathrm{n}^{*}=5.2 \mathrm{H}_{2} \mathrm{SO}_{4}$ molecules for the ternary system is derived. $\mathrm{RH}=15 \%$, $\left[\mathrm{NH}_{3}\right]=0.08 \mathrm{ppb}$, Temperature $\sim 295 \mathrm{~K}$. From [17].

the involvement of a charged core ion. It has been recognized more than a hundred years ago that ion-induced nucleation is a very efficient process of particle nucleation and the invention of the cloud chamber by C.T.R. Wilson was used in elementary particle physics for decades in order to characterize ionizing radiation $[42,43]$. As ion clusters are more easily observed and quantitatively characterized than neutral clusters, a microscopic description beyond the limitations of classical nucleation theory became available $[32,44]$.

In the atmosphere, ions are formed mostly from galactic cosmic rays and the ion-induced nucleation mechanism could mean a small but relatively permanent source of new particles in the atmosphere. It has been speculated that variations of galactic cosmic rays could therefore have an influence on clouds, precipitation and climate [45-47]. Studies to characterize the relevance of this process by aerosol chamber experiments at the European Organization for Nuclear Research (CERN) are ongoing [48].

Atmospheric aerosol nucleation always competes with the uptake of condensable gases on the already existing aerosol particles. Nucleation will only occur, if the production of condensable species is faster than condensation on the pre-existent particles. The concept of the condensational sink (CS) has been established to characterize and model the losses of the condensing molecules on pre-existing particles [49].

\section{Recent developments}

Among the many studies on atmospheric aerosol nucleation, two interesting new studies are briefly introduced and discussed here. These recent studies presented new findings and put up new hypotheses which - if correct - would change our understanding of atmospheric nucleation considerably.

\subsection{Field measurements of nucleation with direct observation of clusters $<3 \mathbf{n m}$}

The first study was presented by Kulmala et al. [50]. Using several new instruments such as a NAIS (Neutral Air Ion Spectrometer) and a mixing-type Condensation Particle Counter (CPC), atmospheric measurements of clusters and aerosol particles below $3 \mathrm{~nm}$ size were made. The continuous existence of a pool of particles with sizes around $1.5 \mathrm{~nm}$ was detected at these measurements in Hyytiälä, Finland. The authors assume therefore that in this case nucleation bursts like the one displayed in Figure 6 are not limited by the nucleation itself, but rather by 


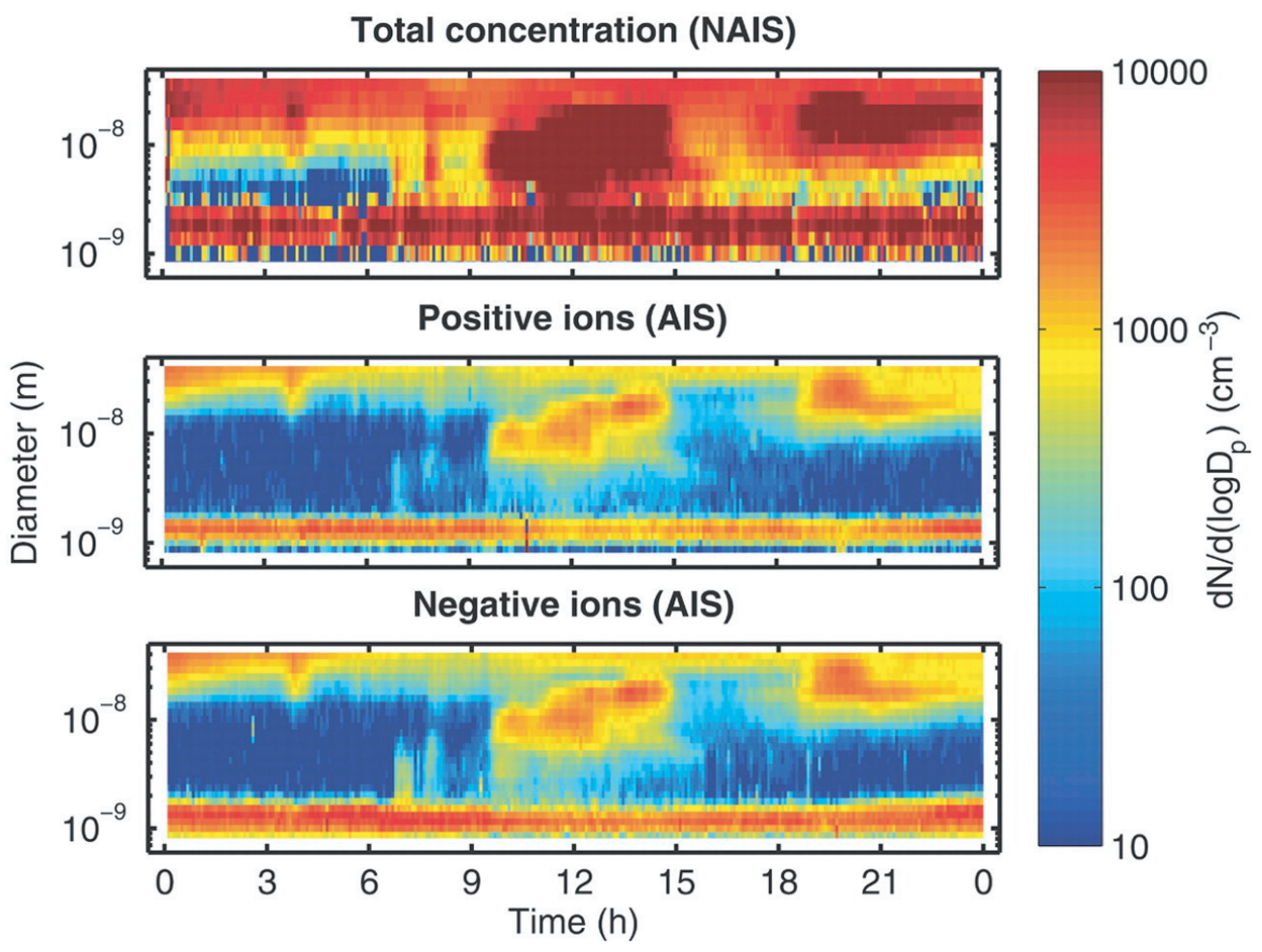

Fig. 6. Nucleation event observed at Hyytiälä on 23 April 2006 for neutral clusters with the Neutral Air Ion Spectrometer NAIS, upper panel, and for charged clusters with the Air Ion Spectrometer (AIS) in the lower panels. Measurements start at sizes $<1 \mathrm{~nm}$. A mode of neutral particles of $\sim 1.5 \mathrm{~nm}$ size seems to be always present, similar to the mode of air ions at this size. The neutral clusters cannot be formed from recombination of charged clusters alone. From [50].

the growth process: a burst that can be observed by conventional aerosol instrumentation will happen when large amounts of condensable organic molecules are produced by photochemical processes and the $1.5 \mathrm{~nm}$ clusters are then activated, i.e. they grow by condensation to detectable sizes $>3 \mathrm{~nm}$. The $1.5 \mathrm{~nm}$ clusters - whichever way they are formed and whatever the chemical composition of these clusters may be - must form continuously because otherwise they would be lost within minutes by coagulation with larger aerosol particles and a continuous population of these clusters could not be maintained.

It is also important to note that the observed $1.5 \mathrm{~nm}$ clusters are not ion clusters. It has been known for a long time that ion clusters in this size range exist in the atmosphere, but the authors demonstrate that an ion-induced nucleation process by activation of these ion clusters can only account for less than $10 \%$ of the observed particles that grow to sizes $>3 \mathrm{~nm}$.

\subsection{Laboratory investigations indicating a new sulphur oxidation chemistry relevant for atmospheric aerosol nucleation}

The second recent study was presented by Berndt et al. [51]. These authors carried out a laboratory study on binary homogeneous nucleation of sulphuric acid and water, using a vertical laminar flow tube reactor. Here the gaseous $\mathrm{H}_{2} \mathrm{SO}_{4}$ was produced in two different ways: a) by evaporating $\mathrm{H}_{2} \mathrm{SO}_{4}$ from a liquid reservoir (saturator) and b) by reacting $\mathrm{SO}_{2}$ with $\mathrm{OH}$ (produced from photolysis of $\mathrm{O}_{3}$ by UV light) in the gas phase by reactions (R1-R3). They demonstrate that a substantial difference exists in the observed particle production, depending on the way the $\mathrm{H}_{2} \mathrm{SO}_{4}$ was produced. As shown in Figure 7, small amounts of new particles $\left(<10 \mathrm{~cm}^{-3}\right)$ are observed when the gaseous $\mathrm{H}_{2} \mathrm{SO}_{4}$ stems from the vaporized liquid. In contrast, large amounts of particles $\left(\sim 5 \times 10^{4} \mathrm{~cm}^{-3}\right)$ are formed when $\mathrm{H}_{2} \mathrm{SO}_{4}$ is produced via the 


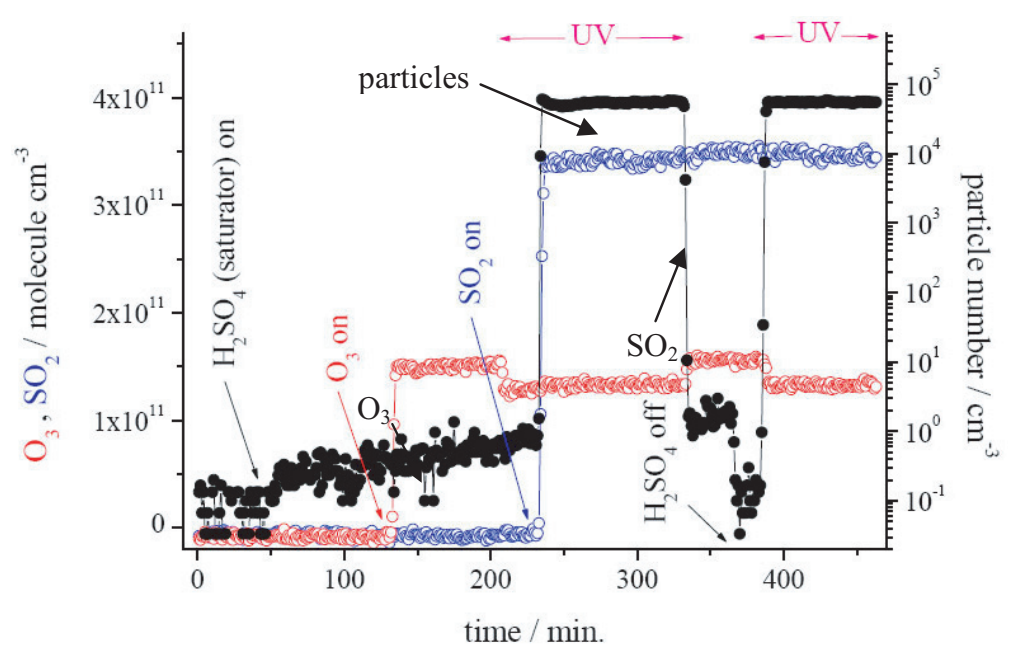

Fig. 7. Particle nucleation observed after evaporation of liquid sulphuric acid (saturator) and after oxidation of sulphur dioxide $\left(\mathrm{SO}_{2}\right)$ by the hydroxyl radical $(\mathrm{OH})$. $\mathrm{OH}$ is produced from photolysis of ozone $\left(\mathrm{O}_{3}\right)$ by UV light. Much higher particle numbers are observed from the $\mathrm{SO}_{2}+\mathrm{OH}$ reaction although the expected $\mathrm{H}_{2} \mathrm{SO}_{4}$ is lower in this case. This may indicate the presence of another oxidized sulphur compound produced from the $\mathrm{SO}_{2}$ oxidation that is responsible for nucleation other than $\mathrm{H}_{2} \mathrm{SO}_{4}$. From [51].

$\mathrm{SO}_{2}+\mathrm{OH}$ reaction scheme. The calculations of the concentration of gaseous sulphuric acid in the flow reactor show that for the production of the few particles with $\mathrm{H}_{2} \mathrm{SO}_{4}$ from the liquid reservoir, maximum $\mathrm{H}_{2} \mathrm{SO}_{4}$ gas phase concentrations in the reactor of $>1 \times 10^{9} \mathrm{~cm}^{-3}$ are needed, while the large amounts of particles are produced already at calculated maximum gas phase concentrations of $\sim 2 \times 10^{8} \mathrm{~cm}^{-3}$ ! This surprising finding was interpreted as a hint that additional chemical reactions are taking place during $\mathrm{SO}_{2}$ gas phase oxidation besides (R1-R3) in which another oxidized sulphur compound is produced that nucleates more easily than the sulphuric acid itself. It is suggested that the peroxo-type radical $\mathrm{HOSO}_{2} \mathrm{O}_{2}$ could be a potential candidate produced from the $\mathrm{HOSO}_{2}+\mathrm{O}_{2}$ reaction that might be the key substance that leads to products that nucleate much more easily than the gas phase sulphuric acid. This new chemistry scheme would resolve one longstanding problem that binary sulphuric acid nucleation in the laboratory needs concentrations of gaseous $\mathrm{H}_{2} \mathrm{SO}_{4}>1 \times 10^{9} \mathrm{~cm}^{-3}$ while gaseous $\mathrm{H}_{2} \mathrm{SO}_{4}$ in the atmosphere rarely exceeds $1 \times 10^{7} \mathrm{~cm}^{-3}$ and nucleation events are frequently observed at these much lower concentrations while numerous indications exist that some sulphur compound is involved in the nucleation process.

This would also be in line with the fact that several studies on atmospheric nucleation involving sulphuric acid indicate that the nucleation rate depends on $\left[\mathrm{H}_{2} \mathrm{SO}_{4}\right]^{\mathrm{n}}$ with $\mathrm{n}$ between 1 and $2[26,27,52]$ and therefore, according to equation (4) the critical cluster would involve just one or two $\mathrm{H}_{2} \mathrm{SO}_{4}$ molecules, while the results from Ball et al. [25], where gaseous $\mathrm{H}_{2} \mathrm{SO}_{4}$ was produced from evaporating the liquid, show that the critical cluster should involve considerably more $\mathrm{H}_{2} \mathrm{SO}_{4}$ molecules (Figure 4). For $\mathrm{n} \leq 2$ the nucleation barrier vanishes and the cluster growth would be just kinetically limited. Another approach to explain this behaviour is given by cluster activation theory [27].

Currently the findings from these two studies have not been verified by independent experiments or other field observations. Also, it has to be noted that, so far, in the study by Berndt et al. the $\mathrm{H}_{2} \mathrm{SO}_{4}$ gas phase concentration was not directly measured. It will be interesting to see if these new hypotheses can be confirmed by further studies in the future.

\section{Summary}

The formation of new particles from gaseous precursor substances in the Earth's atmosphere is a process that takes place frequently. Often nucleation bursts are observed where many 
new particles are formed simultaneously. It is conceivable that a slow but more continuous production of new particles also takes place but this process is harder to detect by the existing measurement techniques. Sulphuric acid is currently thought to be a key player for atmospheric nucleation, except for coastal areas where iodine oxides are most likely the nucleating substances. Other substances, such as other oxidized sulphur compounds or organic substances might be important for atmospheric nucleation as well. Binary or ternary homogeneous nucleation or ion-induced nucleation are considered as the most important nucleation mechanisms in the atmosphere. Probably, nucleation via all three mechanisms is taking place in the atmosphere but with variable prominence. In many cases the nucleation barrier seems to be very small, between 1 and 2 molecules only, indicating that rather an activation process or a kinetically limited nucleation is taking place. The growth of the freshly nucleated particles is often decoupled from the nucleation itself. This growth process might be more limiting for the production of particles of sizes $>3 \mathrm{~nm}$ than the nucleation in some cases.

Classical nucleation theory, while qualitatively correct, is not able to predict atmospheric particle nucleation on a quantitative scale because the bulk properties that are used in the classical approach are inadequate to describe the properties of clusters that consist of only a few molecules. Further research is needed to find out which chemical substances undergo nucleation and which substances take part in the growth process for the various atmospheric situations in which nucleation occurs. These substances have to be measured quantitatively.

In how far the formation of clouds is influenced by aerosol nucleation processes is a topic of high scientific relevance $[31,53]$. Especially the question in how far anthropogenic emissions affect the nucleation and therefore cloud formation, cloud properties and precipitation requires further in depth investigation.

\section{References}

1. U. Dusek, G.P. Frank, L. Hildebrandt, J. Curtius, J. Schneider, S. Walter, D. Chand, F. Drewnick, S. Hings, D. Jung, S. Borrmann, M.O. Andreae, Science 312, 1375 (2006)

2. J.H. Seinfeld, S.N. Pandis, Atmospheric Chemistry and Physics - From Air Pollution to Climate Change (New York: John Wiley and Sons, Inc., 1998)

3. J.M. Makela, P. Aalto, V. Jokinen, T. Pohja, A. Nissinen, S. Palmroth, T. Markkanen, K. Seitsonen, H. Lihavainen, M. Kulmala, Geophys. Res. Lett. 24, 1219 (1997)

4. C.D. O'Dowd, T. Hoffmann, Environ. Chem. 2, 245 (2005)

5. C.D. O'Dowd, J.L. Jimenez, R. Bahreini, R.C. Flagan, J.H. Seinfeld, K. Hameri, L. Pirjola, M. Kulmala, S.G. Jennings, T. Hoffmann, Nature 417, 632 (2002)

6. P.H. McMurry, F.L. Eisele, J. Geophys. Res. Atmos. 110, D22S01 (2005)

7. S.H. Lee, J.M. Reeves, J.C. Wilson, D.E. Hunton, A.A. Viggiano, T.M. Miller, J.O. Ballenthin, L.R. Lait, Science 301, 1886 (2003)

8. C.A. Brock, P. Hamill, J.C. Wilson, H.H. Jonsson, K.R. Chan, Science 270, 1650 (1995)

9. M. de Reus, J. Strom, J. Curtius, L. Pirjola, E. Vignati, F. Arnold, H.C. Hansson, M. Kulmala, J. Lelieveld, F. Raes, J. Geophys. Res. Atmos. 105, 24751 (2000)

10. R.J. Weber, P.H. McMurry, R.L. Mauldin, D.J. Tanner, F.L. Eisele, A.D. Clarke, V.N. Kapustin, Geophys. Res. Lett. 26, 307 (1999)

11. T. Suni, et al., Atmos. Chem. Phys. 8, 129 (2008)

12. L. Laakso, et al., Atmos. Chem. Phys. 8, 4823 (2008)

13. M. Kulmala, H. Vehkamaki, T. Petajda, M. Dal Maso, A. Lauri, V.M. Kerminen, W. Birmili, P.H. McMurry, J. Aerosol Sci. 35, 143 (2004)

14. J. Curtius, Comptes Rendus Phys. 7, 1027 (2006)

15. A. Laaksonen, V. Talanquer, D.W. Oxtoby, Ann. Rev. Phys. Chem. 46, 489 (1995)

16. M. Boy, M. Kulmala, Atmos. Chem. Phys. 2, 1 (2002)

17. S.M. Ball, D.R. Hanson, F.L. Eisele, P.H. McMurry, J. Geophys. Res. Atmos. 104, 23709 (1999)

18. J. Merikanto, I. Napari, H. Vehkamaki, T. Anttila, M. Kulmala, J. Geophys. Res. Atmos. 112, (2007)

19. R.Y. Zhang, I. Suh, J. Zhao, D. Zhang, E.C. Fortner, X.X. Tie, L.T. Molina, M.J. Molina, Science 304, 1487 (2004)

20. H. Yu, et al., Atmos. Chem. Phys. 6, 613 (2006) 
21. U. Lohmann, J. Feichter, Atmos. Chem. Phys. 5, 715 (2005)

22. A. Ibald-Mulli, H.E. Wichmann, W. Kreyling, A. Peters, J. Aerosol Medicine-Deposition Clearance Effects Lung 15, 189 (2002)

23. C.A. Pope, R.T. Burnett, M.J. Thun, E.E. Calle, D. Krewski, K. Ito, G.D. Thurston, Jama-J. Amer. Med. Ass. 287, 1132 (2002)

24. W.R. Stockwell, J.G. Calvert Atmos. Environ. 17, 2231 (1983)

25. E.R. Lovejoy, D.R. Hanson, L.G. Huey, J. Phys. Chem. 100, 19911 (1996)

26. V. Fiedler, M. Dal Maso, M. Boy, H. Aufmhoff, J. Hoffmann, T. Schuck, W. Birmili, M. Hanke, J. Uecker, F. Arnold, M. Kulmala, Atmos. Chem. Phys. 5, 1773 (2005)

27. M. Kulmala, K.E.J. Lehtinen, A. Laaksonen, Atmos. Chem. Phys. 6, 787 (2006)

28. M. Kulmala, U. Pirjola, J.M. Makela, Nature 404, 66 (2000)

29. J.B. Burkholder, J. Curtius, A.R. Ravishankara, E.R. Lovejoy, Atmos. Chem. Phys. 4, 19 (2004)

30. D.V. Spracklen, K.S. Carslaw, M. Kulmala, V.M. Kerminen, G.W. Mann, S.L. Sihto, Atmos. Chem. Phys. 6, 5631 (2006)

31. D.V. Spracklen, K.S. Carslaw, M. Kulmala, V.M. Kerminen, S.L. Sihto, I. Riipinen, J. Merikanto, G.W. Mann, M.P. Chipperfield, A. Wiedensohler, W. Birmili, H. Lihavainen, Geophys. Res. Lett. 35 (2008)

32. J. Curtius, E.R. Lovejoy, K.D. Froyd, Space Sci. Rev. 125, 159 (2006)

33. P.M. Holland, A.W. Castleman Jr., J. Phys. Chem. 86, 4181 (1982)

34. D. Kashiev, J. Chem. Phys. 76, 5098 (1982)

35. R. Strey, Y. Viisanen, J. Chem. Phys. 99, 4693 (1993)

36. Y. Viisanen, R. Strey, H. Reiss, J. Chem. Phys. 99, 4680 (1993)

37. H. Reiss, J. Chem. Phys. 18, 840 (1950)

38. G.J. Doyle, J. Chem. Phys. 35, 795 (1961)

39. A. Jaecker-Voirol, P. Mirabel, Atmos. Environ. 23, 2053 (1988)

40. H. Vehkamaki, M. Kulmala, I. Napari, K.E.J. Lehtinen, C. Timmreck, M. Noppel, A. Laaksonen, J. Geophys. Res. Atmos. 107, 4622 (2002) doi:4610.1029/2002JD002184

41. F.Q. Yu, J. Geophys. Res. Atmos. 111, D04201 (2006) doi:04210.01029/02005JD006358

42. C.T.R. Wilson, Nature 69, 104 (1904)

43. C.T.R. Wilson, Proc. Royal Soc. London Ser. 85, 285 (1911)

44. E.R. Lovejoy, J. Curtius, K.D. Froyd, J. Geophys. Res. Atmos. 109, D08204 (2004) doi:08210.01029/02003JD004460

45. N.D. Marsh, H. Svensmark, Phys. Rev. Lett. 85, 5004 (2000)

46. K.S. Carslaw, R.G. Harrison, J. Kirkby, Science 298, 1732 (2002)

47. J. Kirkby, Surv. Geophys. 28, 333 (2007)

48. J. Kanipe, Nature 443, 141 (2008)

49. L. Pirjola, M. Kulmala, M. Wilck, A. Bischoff, F. Stratmann, E. Otto, J. Aerosol Sci. 30, 1079 (1999)

50. M. Kulmala, et al., Science 318, 89 (2007)

51. T. Berndt, F. Stratmann, S. Bräsel, J. Heintzenberg, A. Laaksonen, M. Kulmala, Atmos. Chem. Phys. Discuss. 8, 9761 (2008)

52. R.J. Weber, J.J. Marti, P.H. McMurry, F.L. Eisele, D.J. Tanner, A. Jefferson, J. Geophys. Res. Atmos. 102, 4375 (1997)

53. J.R. Pierce, P.J. Adams, Nucl. Prim. Emiss. Rates 8, 16291 (2008) 
